3 Anderson D. Age discrimination in mental health services needs to be understood. Psychiatrist 2011; 35: 1-4.

4 Draper B, Anderson D. The baby boomers are already here - but do we have sufficient workforce in old age psychiatry? Int Psychogeriatrics 2010; 22: 947-9.

5 Centre for Workforce Intelligence. Recommendation for Medical Specialty Training 2011. CFWI, 2010.

David N. Anderson, consultant old age psychiatrist, Mersey Care NHS Trust, Liverpool, UK, email: david.anderson@merseycare.nhs.uk doi: $10.1192 / \mathrm{pb} .36 .9 .357 \mathrm{a}$

\section{Are the results only limited by ethnicity?}

We found the article by Choudhry et al ${ }^{1}$ a very interesting read. Although retrospective, given a good sample size and appropriate period of follow up, the results are informative and useful. We applaud the effort to identify the subgroup of opiate-free patients who could benefit the most from naltrexone for relapse prevention.

It is striking that the study population had Asian men in such a high proportion, which certainly makes the sample atypical. The authors have mentioned the associated factors predicting a favourable outcome for this group. Could we request the authors to comment on the possible differences in naltrexone metabolism which might influence outcomes? There is now evidence to support the fact that pharmacogenetic characteristics of Asian population are associated with improved biobehavioural and clinical response to naltrexone. ${ }^{2}$
The results might have further been affected by personality characteristics within the study group. This, too, would have been valuable information.

We also wondered why the naltrexone challenge was only done for $80.3 \%$ of the study sample. Information about how many failed the challenge would be useful as focusing only on the ones who were successful again selects the highly motivated group, which may not be representative. Finally, we wondered whether the authors might want to comment on the wider context given that the results have shown again that the retention rates in naltrexone treatment are not very high. It is worth noting that even if retained in treatment, efficacy of oral naltrexone in relapse prevention for opioid use is not significant ${ }^{3}$ compared with placebo.

1 Chaudhry ZA, Sultan J, Alam F. Predictors for retention in treatment with a UK community-based naltrexone programme for opioid dependence. Psychiatrist 2012; 36: 218-24.

2 Ray LA, Bujarski S, Chin PF, Miotto K. Pharmacogenetics of naltrexone in Asian Americans: a randomized placebo-controlled laboratory study. Neuropsychopharmacol 2012; 37: 445-55.

3 Minozzi S, Amato L, Vecchi S, Davoli M, Kirchmayer U, Verster A. Ora naltrexone maintenance treatment for opioid dependence. Cochrane Database Syst Rev 2011; 4: CD001333.

Chaitra Suresh, senior registrar, ST6 in addictions psychiatry, email: chaitra.suresh@nhs.net, Adetokunbo Shangobiyi, associate specialist in addictions psychiatry, and Mukesh Kripalani, consultant psychiatrist, all at Tees, Esk and Wear Valleys NHS Foundation Trust, County Durham, UK.

doi: $10.1192 / p b .36 .9 .358$ 